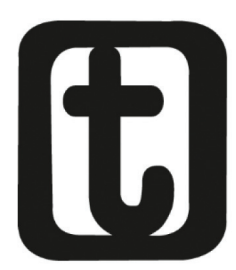

\title{
COMO AS NECESSIDADES DA ACUMULAÇÃO LIMITAM AS POSSIBILIDADES DOS DIREITOS ŚOCIAIS?
}

\author{
How the needs of accumulation limit the possibilities \\ of the social rights?
}

\section{Álvaro Andre Santarém Amorim}

\section{RESUMO}

O paradigma da acumulação é determinante para as tendências e configuraçõos dos direitos sociais. Este artigo procura articular fundamentos teóricos da economia política do trabalho com as configurações empíricas presentes no processo de acumulação da riqueza de nossa sociedade e com os direitos sociais. Os dados empíricos evidenciam as questões do orçamento, do emprego, da riqueza social e da renda do trabalho.Conclui que os efeitos da superpopulação relativa somados aos efeitos da dinâmica do orçamento público qualificam e determinam de forma ampla como as necessidades da acumulação limitam as possibilidades dos direitos sociais.

\section{PALAVRAS-CHAVE}

Direitos Sociais. Acumulação. Riqueza.

\footnotetext{
${ }^{1}$ Bacharel em Administração pela Universidade de Brasília. Mestre em Política Social pela Universidade de Brasília. Integrante do Grupo de Estudos e Pesquisas sobre Seguridade Social e Trabalho da Universidade de Brasília. Email: alvarogestao@gmail.com.
} 


\section{ABSTRACT}

The paradigm of accumulation is determinant for tendencies and configurations of social rights. This article looks to articulate theoretical fundaments of political economy of labor with the empirical configurations present in the process of wealth accumulation of our society and with the social rights. The empiric data shows the questions of budget, employment, social wealth and labor income. Concludes that the effects of the relative overpopulation added to the effects of the public budget qualifies and determines in a largely way as the needs of accumulation limits the possibilities of the social rights.

\section{KEYWORDS}

Social Rights. Accumulation. Wealth.

\section{INTRODUÇÃO}

O paradigma da acumulação é determinante para as tendências e configurações dos direitos sociais. O Estado,como o grande materializador dos direitos sociais, enfrenta consequentemente a limitação e a interação do processo de acumulação de nossa sociedade. Este artigo procura articular teórica e empiricamente o paradigma presente nesse processo após 1995. Para isso, ganham destaque pressupostos e desenvolvimentos teóricos da economia política do trabalho fundamentados em Marx (2009), Rosdolsky (2001), Ianni (2004) e Pochmann (2009). Os dados empíricos que aproximam o paradigma desenvolvido evidenciam as questões do orçamento, do emprego, da riqueza social e da renda do trabalho.

O Estado, sendo o executor da proteção social, atua imerso, estrutural e conjunturalmente, numa elevada concentração de riquezas e desigualdades. Entre os aspectos fundamentais do movimento e interação da estrutura econômica com suas conjunturas sociais, destaca-se a superpopulação relativa². Muito embora "população

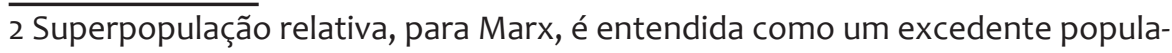


que não tem sua segurança de renda garantida pelo trabalho" bem como "população caracterizada na condição de pobreza extrema" não sejam conceitos idênticos ao de superpopulação relativa, ambos os conceitos descrevem grupos populacionais que não têm suas necessidades básicas atendidas, assim como não se formaram em função de alterações demográficas (PEREIRA; AMORIM, 2010). Entende-se que a superpopulação relativa e as formas de pauperização são construídas em virtude das necessidades e formas de organização das relações econômicas e sociais de cada modo de produção. Em nossa organização societária, a superpopulação relativa aparece ora de forma aguda, nas crises, ora de forma branda, nos períodos de desenvolvimento econômico, mas necessariamente é permanente em toda a história desse sistema (MARX, 2008).

\section{PROCESSOS FUNDAMENTAIS DA ACUMULAÇÃO}

Existem processos fundamentais de acumulação que determinam em grande medida a estrutura de riqueza e a situação da classe trabalhadora. Esse entendimento essencial estava presente originalmente em Marx, no capítulo 23 de O Capital, no qual realizou suas reflexões sobre as formas de alteração da composição do capital e a formação do pauperismo. Cabe destacar que o fenômeno da acumulação e do pauperismo é mediado pelas relações estabelecidas com a força de trabalho, sendo que o valor e a forma de compensação da força de trabalho (o salário) têm elementos tanto físicos e individuais quanto históricos, sociais e coletivos (MARX, 2009).

A compreensão da situação da classe trabalhadora e, especificamente, dos diretos sociais não pode ser dissociadado processo de acumulação de riqueza em nossa sociedade. Os fundamentos dessa compreensão estão imbricados nas relações de três elementos estruturantes do nosso modo de produção: geração de sobrevalor; exploração da força de trabalho; geração de formas

cional não empregado. De acordo com esse autor, "[...] ela constitui um exército industrial de reserva disponível, que pertence ao capital de maneira tão absoluta, como se ele o tivesse criado à própria custa" (MARX, 1988, p. 191). Assim, gerada inicialmente por meio da expropriação das terras dos campesinos no século XIX, essa superpopulação de proletários não empregados é essencial para o desenvolvimento do capitalismo (PEREIRA; AMORIM, 2010). 
de pauperismo. Esses fundamentos clássicos estão presentes na lei geral de acumulação capitalista. Seguiremos sinteticamente o percurso de Marx (2009) na exposição dos movimentos da lei geral de acumulação capitalista, procurando explicitar empiricamente nexos com a realidade do Brasil após 1995.

Existem circunstâncias em que o processo de acumulação pode provocar alta dos salários (MARX, 2009, p. 716). Em geral, isso ocorre quando a composição variável (salários) da riqueza global aumenta paralelamente ao processo de acumulação. Em vez de ganharem em intensidade, a exploração e a dominação capitalista ganham em extensão à medida que aumenta o capital. Isso ocorre tendencialmente, quando se necessita de um número maior de trabalhadores em determinado ramo já existente da produção, ou quando um novo nicho de produção começa a ser explorado (um exemplo é a exploração das reservas de petróleo do pré-sal no Brasil). Nessa situação, o aumento da massa de salário indica uma diminuição relativa do trabalho gratuito que o trabalhador deve sempre proporcionar ao empregador, sendo que esse aumento da massa de salário (índice de capital variável) pode ser descrito pelo número de trabalhadores, tempo de trabalho ou valor da força de trabalho. Porém essa alta da massa de salário, ao mesmo tempo que é um limite à acumulação, estimula a produção de tecnologias que elevem o valor do capital fixo (propriedades como maquinário), provocando uma nova mudança na composição do capital que, em geral, traz por consequência a baixa da massa geral do salários.

No modo de produção de nossa sociedade, o trabalhador existe para as necessidades de expansão dos valores existentes, em vez de as riquezas materiais existirem para as necessidades de desenvolvimento dos trabalhadores (MARX, 2009, p. 724). Produzir mais-valia é a lei absoluta desse modo de produção (MARX, 2009, p. 721). Expressando matematicamente essa relação, temos que: a magnitude da acumulação é variável independente e o montante dos salários é variável dependente, não sendo verdadeira a afirmação oposta. Nesse processo de acumulação, o desenvolvimento da produtividade do trabalho social se torna a mais poderosa alavanca da acumulação (MARX, 2009, p. 725). 
O progresso e o desenvolvimento das forças produtivas (trabaIhadores, maquinários, tecnologias da informação) elevam historicamente e consistentemente sua capacidade produtiva, seja pela incorporação de novos maquinários, seja pela elevação da escolaridade. Entretanto, o aumento da massa de valor dos meios de produção (capital fixo) reflete-se no aumento da parte constante (propriedades) à custa da parte variável (salários).

Uma evidência que explicita a relação na mudança da composição orgânica do capital é a relação entre pessoal ocupado e produtividade. Por exemplo, no nicho de produção da indústria de transformação no Estado de São Paulo, de 1985 a 1995, tanto o número de ocupados quanto a quantidade de horas pagas decaíram mais de $20 \%$ e, no mesmo período, a produtividade aumentou mais de $20 \%$ (CARVALHO; BERNARDES, 1996).O aumento da produtividade com diminuição da quantidade de ocupados auxilia também a compreensão de que o processo de variação na composição orgânica do capital, nas últimas décadas, tem ocorrido tanto no meio urbano quanto no rural. Esse processo demarca importantes configurações da elevada taxa de desemprego, desocupação e precarização do trabalho nas últimas décadas (POCHMANN, 2009).

Outro importante movimento do processo de acumulação é o de concentração e centralização da riqueza. No entanto, em nossa sociedade, a concorrência e o crédito estão entre os mais poderosos centros de impulsão e desenvolvimento de riqueza. Esse processo de concentração e centralização, que também reduz a procura e a massa de salários advindos do trabalho, vem sendo amplamente estudado por pesquisadores da mundialização, como François Chesnais. Entre os muitos apontamentos de Chesnais (1996, p. 95), destaca-se a concentração de produção e comercialização em escala internacional, na qual poucas empresas dominam mais de 50\% de toda a produção mundial nos seguintes setores: automóveis, produtos médicos, produtos petroquímicos e informática.

A análise da relação entre movimentos populacionais e acumulação capitalista é outro elemento fundamental. A população trabalhadora, ao produzir a acumulação do capital, produz, em proporções crescentes, os meios que fazem dela, relativamente, uma população supérflua (MARX, 2009, p. 734). Nesse senti- 
do, a população excedente é produto necessário da acumulação ou do desenvolvimento da riqueza em nossa atual organização societária. Isso porque é necessário que exista força de trabalho disponível para cada ciclo de expansão da riqueza (tanto para crescimento de nichos antigos de mercado quanto para novos empreendimentos). A não disponibilidade da força de trabalho limitaria em grande medida os novos ciclos de expansão da riqueza. Ressalte-se que a perspectiva de Marx quanto a essa população excedente ou superpopulação era sempre em termos relativos, contrapondo-se a diversos autores da época que se colocavam na perspectiva de superpopulação absoluta, como Thomas Malthus.

Algumas evidências confirmam a permanência do movimento analisado por Marx, contido na relação entre superpopulação e acumulação de riqueza do Brasil nas últimas décadas. Como se observa na Tabela 1, ao identificarmos o aumento do Produto Interno Bruto (PIB) Real de 1945 a 2009, houve uma elevação da produção da riqueza social. O PIB per capita aumentou; todavia, é necessário considerar os efeitos do processo de acumulação de riqueza em nossa sociedade, principalmente em relação à geração e manutenção da superpopulação relativa.

Tabela 1 - PIB Real, População e PIB por pessoa de 1945 a 2009

\begin{tabular}{|l|r|r|r|r|r|r|r|}
\hline \multicolumn{1}{|c|}{ Ano } & \multicolumn{1}{c|}{1945} & \multicolumn{1}{c|}{1955} & \multicolumn{1}{c|}{1965} & \multicolumn{1}{c|}{1975} & \multicolumn{1}{c|}{1980} & \multicolumn{1}{c|}{1985} & 1986 \\
\hline PIB real & 129.381 .702 .603 & 257.869 .598 .942 & 469.025 .172 .055 & 1.118 .327 .858 .565 & 1.583 .388 .911 .953 & 1.686 .793 .578 .955 & 1.813 .134 .418 .019 \\
\hline População & 45.736 .565 & 60.150 .121 & 81.252 .577 & 105.380 .235 & 118.562 .549 & 132.999 .282 & 135.814 .249 \\
\hline PIB Per Capita & 2.829 & 4.287 & 5.772 & 10.612 & 13.355 & 12.683 & 13.350 \\
\hline 1987 & 1988 & 1989 & 1990 & 1991 & 1992 & 1993 & 1994 \\
\hline 1.877 .138 .062 .975 & 1.876 .011 .780 .137 & 1.935 .293 .752 .390 & 1.851 .108 .474 .161 & 1.870 .202 .367 .035 & 1.861 .470 .113 .073 & 1.948 .310 .503 .705 & 2.052 .240 .397 .490 \\
\hline 138.585 .894 & 141.312 .997 & 143.997 .246 & 146.592 .579 & 149.094 .266 & 151.546 .843 & 153.985 .576 & 156.430 .949 \\
\hline 13.545 & 13.276 & 13.440 & 12.628 & 12.544 & 12.283 & 12.653 & 13.119 \\
\hline 1995 & 1996 & 1997 & 1998 & 1999 & 2000 & 2001 & 2002 \\
\hline 2.142 .884 .407 .946 & 2.188 .967 .112 .989 & 2.262 .851 .276 .565 & 2.263 .651 .096 .631 & 2.269 .402 .543 .057 & 2.367 .127 .257 .053 & 2.398 .210 .450 .317 & 2.461 .957 .140 .452 \\
\hline 158.874 .963 & 161.323 .169 & 163.779 .827 & 166.252 .088 & 168.753 .552 & 171.279 .882 & 173.808 .010 & 176.303 .919 \\
\hline 13.488 & 13.569 & 13.816 & 13.616 & 13.448 & 13.820 & 13.798 & 13.964 \\
\hline 2003 & 2004 & 2005 & 2006 & 2007 & 2008 & 2009 & 2010 \\
\hline 2.490 .186 .429 .057 & 2.632 .433 .158 .593 & 2.715 .609 .454 .481 & 2.823 .067 .072 .621 & 2.995 .031 .680 .075 & 3.148 .857 .550 .574 & 3.143 .014 .695 .014 & - \\
\hline 178.741 .412 & 181.105 .601 & 183.383 .216 & 185.564 .212 & 187.641 .714 & 189.612 .814 & 191.480 .630 & - \\
\hline 13.932 & 14.535 & 14.808 & 15.213 & 15.961 & 16.607 & 16.414 & - \\
\hline
\end{tabular}

Fonte: IPEADATA: Base de dados econômicos e financeiros.

Obs.: Valores em $\mathrm{R} \$$ a preços de 2009. 
A consistente elevação da riqueza social torna-se importante paradigma de análise da relação com a superpopulação, quando analisamos nas Tabelas 2 e 3 o quadro de movimentação de empregos formais e população ocupada, desempregada e sem renda do trabalho. Destaca-se também a situação emblemática da enorme parcela da população de 25 a 59 anos colocada na situação de força de trabalho disponível e sem renda do trabalho, independentemente da produção da riqueza social ter se elevado consideravelmente entre 2001 e 2008.

Tabela 2 - Movimentação de empregos formais

\begin{tabular}{|c|c|c|c|c|}
\hline Ano & Admissões - A & Desligamentos - D & Fluxo A-D & $\begin{array}{c}\text { Saldo da população } \\
\text { de 25 a 59 anos sem } \\
\text { renda do trabalho }\end{array}$ \\
\hline 1998 & 8.067 .389 & 8.649 .134 & -581.745 & - \\
\hline 1999 & 8.181 .425 & 8.377 .426 & -196.001 & - \\
\hline 2000 & 9.668 .132 & 9.010 .536 & 657.596 & - \\
\hline 2001 & 10.351 .643 & 9.760 .564 & 591.079 & 20.607 .000 \\
\hline 2002 & 9.812 .379 & 9.049 .965 & 762.414 & 20.341 .000 \\
\hline 2003 & 9.809 .343 & 9.163 .910 & 645.433 & 21.039 .000 \\
\hline 2004 & 11.296 .496 & 9.773 .220 & 1.523 .276 & 20.786 .000 \\
\hline 2005 & 12.179 .001 & 10.925 .020 & 1.253 .981 & 20.921 .000 \\
\hline 2006 & 12.831 .149 & 11.602 .463 & 1.228 .686 & 21.185 .000 \\
\hline 2007 & 14.341 .289 & 12.723 .897 & 1.617 .392 & 22.056 .000 \\
\hline 2008 & 16.659 .331 & 15.207 .127 & 1.452 .204 & 21.679 .000 \\
\hline 2009 & 16.187 .640 & 15.192 .530 & 995.110 & - \\
\hline Total & 139.385 .217 & 129.435 .792 & 9.949 .425 & - \\
\hline
\end{tabular}

Fonte: Cadastro Geral de Empregados e Desempregados - CAGED; Pesquisa Nacional por Amostra de Domicílios (PNAD) de 1998 a 2008.

Observando-se as Tabelas 2 e 3, percebe-se que o saldo entre admissões e desligamentos, apesar de positivo, a partir do ano 2000 em diante, não consegue nem mesmo diminuir consistentemente o número de pessoas de 25 a 59 anos sem renda do trabalho de 2001 a 2008. 
Tabela 3 - Evolução da população ocupada, desempregada e sem renda do trabalhos

\begin{tabular}{|c|c|c|c|c|c|c|c|}
\hline Ano & $\begin{array}{c}\text { Saldo } \\
\text { entre ad- } \\
\text { missões } \\
\text { e desliga- } \\
\text {-mentos } \\
\text { de em- } \\
\text { pregos }\end{array}$ & $\begin{array}{c}\text { Desem- } \\
\text { pre-ga- } \\
\text { dos com } \\
\mathbf{1 5} \text { anos } \\
\text { ou mais }\end{array}$ & $\begin{array}{c}\text { Ocupa- } \\
\text { dos com } \\
\text { ou mais }\end{array}$ & $\begin{array}{c}\text { Ocupa- } \\
\text { dos de } \\
\mathbf{2 5} \text { a 59 } \\
\text { anos }\end{array}$ & $\begin{array}{c}\text { Popu- } \\
\text { lação } \\
\text { Economi- } \\
\text { ca-mente } \\
\text { Ativa de } \\
\mathbf{2 5} \text { a 59 } \\
\text { anos }\end{array}$ & $\begin{array}{c}\text { Popula- } \\
\text { ção NÃ̃ } \\
\text { Economi- } \\
\text {-camente } \\
\text { Ativa de } \\
\mathbf{2 5} \text { a 59 } \\
\text { anos }\end{array}$ & $\begin{array}{c}\text { População } \\
\text { de 25 a 59 } \\
\text { anos sem } \\
\text { renda do } \\
\text { trabalho }\end{array}$ \\
\hline 1998 & -581.745 & 6.595 .979 & 67.470 .575 & - & - & - & - \\
\hline 1999 & -196.001 & 7.537 .464 & 70.748 .595 & - & - & - & - \\
\hline 2000 & 657.596 & - & - & - & - & - & - \\
\hline 2001 & 591.079 & 7.648 .872 & 74.140 .883 & 52.478 .000 & 56.286 .000 & 16.799 .000 & 20.607 .000 \\
\hline 2002 & 762.414 & 7.727 .276 & 77.064 .227 & 54.705 .000 & 58.458 .000 & 16.588 .000 & 20.341 .000 \\
\hline 2003 & 645.433 & 8.456 .803 & 78.440 .374 & 55.861 .000 & 60.072 .000 & 16.828 .000 & 21.039 .000 \\
\hline 2004 & 1.523 .276 & 8.042 .613 & 81.241 .285 & 59.218 .000 & 63.153 .000 & 16.851 .000 & 20.786 .000 \\
\hline 2005 & 1.253 .981 & 8.696 .470 & 83.617 .295 & 61.024 .000 & 65.167 .000 & 16.778 .000 & 20.921 .000 \\
\hline 2006 & 1.228 .686 & 7.969 .317 & 86.042 .321 & 62.993 .000 & 66.918 .000 & 17.260 .000 & 21.185 .000 \\
\hline 2007 & 1.617 .392 & 7.817 .628 & 87.719 .059 & 64.500 .000 & 68.545 .000 & 18.011 .000 & 22.056 .000 \\
\hline 2008 & 1.452 .204 & 6.947 .289 & 89.693 .920 & 66.749 .000 & 70.299 .000 & 18.129 .000 & 21.679 .000 \\
\hline
\end{tabular}

Fonte: Cadastro Geral de Empregados e Desempregados - CAGED; Pesquisa Nacional por Amostra de Domicílios (PNAD) de 1998 a 2008. Obs.: Os dados de população até 2003 excluem a população da área rural de Rondônia, Acre, Amazonas, Roraima, Pará e Amapá. Os dados de ocupação, desemprego e População Economicamente Ativa (PEA) referem-se à semana de referência pesquisada pela PNAD. A População Não Economicamente Ativa corresponde às pessoas não classificadas como ocupadas ou desocupadas e que não estão à procura de emprego.

Outros pontos são importantes de serem destacados. O primeiro é que existe uma relativa estabilidade em números absolutos da população de 25 a 59 anos sem renda do trabalho de 2001 a 2008, mesmo que a população economicamente ativa nessa faixa etária tenha aumentado de aproximadamente 56 milhões em 2001 para 70 milhões em 2008.

O segundo é que, embora o número absoluto de desempregados em 2008 com 15 anos ou mais (aproximadamente 6,9 milhões) seja bem menor que em 2003 (aproximadamente 8,4 milhões), esse número ainda é maior que o de 1998 (aproximadamente 6,5 milhões de pessoas). 
O terceiro ponto é que, ao considerarmos as pessoas de 25 a 59 anos como desocupadas por meio da subtração da População Economicamente Ativa de 25 a 59 anos com a população ocupada de 25 a 59 anos, pode-se observar também que a quantidade de desocupados permanece constante em aproximadamente 4 milhões de pessoas.

O quarto, que a população ocupada com 15 anos ou mais aumentou consistentemente de 1998 a 2008, garantindo que a população em geral sem rendimento do trabalho, e em específico a população de 25 a 59 anos sem rendimento do trabalho, se mantivesse estabilizada mesmo com o crescimento vegetativo que o Brasil possui. Entende-se também que esse quantitativo estabilizado de pessoas de 25 a 59 anos, sem renda do trabalho de 2001 a 2008, não se encontra nessa condição por escolhas ou preferências individuais, mas em decorrência da organização do mercado de trabalho e das condições da estrutura de acumulação.

As transformações advindas do processo de acumulação são acompanhadas de mudanças na gestão organizacional, com redução de níveis hierárquicos (downsizing/delaying) e flexibilidade contratual que acabam por intensificar a precarização das relações de trabalho (MOROSINI, 2001, p. 9). Outro exemplo é o processo de intensificação da força de trabalho evidenciado por Dal Rosso (2008), nos mais diversos nichos da economia do Distrito Federal, entre eles: bancos, finanças, telefonia, comunicação, supermercados, ensino, construção civil e serviço público. Essas configurações são exemplificações que mostram a permanência contemporânea das tendências gerais presentes em O Capital sobre a superpopulação relativa.

Nesse sentido, condena-se uma parte da classe trabalhadora à ociosidade forçada, em virtude do trabalho excessivo da outra parte da população que se torna fonte de enriquecimento dos proprietários dos meios de produção (MARX, 2009, p. 740). Essa determinação se amplia na constatação de que os movimentos gerais dos salários se regulam exclusivamente pela expansão e contração da superpopulação relativa, com mudanças periódicas a cada ciclo da produção (MARX, 2009, p. 741). Associa-se a esse fenômeno o fato de que o incremento absoluto do capital não é acompanhado por 
uma elevação correspondente à demanda geral por força de trabalho. Decorre disso, como se observa acima, que o crescimento econômico, assim como o crescimento do PIB por pessoa, em si, não foi capaz de diminuir a superpopulação relativa.

Destaca-se que houve na indústria brasileira uma elevação da produtividade do trabalhador ${ }^{3}$, com uma diminuição do custo unitário do trabalhador, ou seja, com diminuição relativa da massa de salário da sua força de trabalho, conforme Gráficos 1 e 2.

(nov/2001 $=100$ com ajuste sazonal)

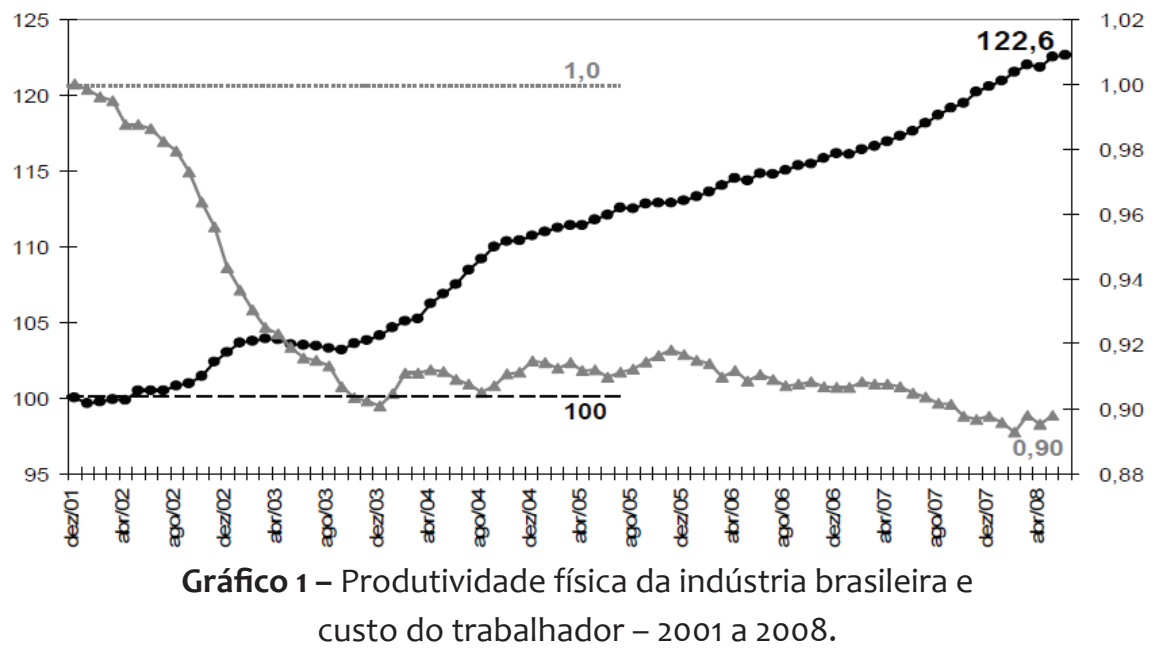

Fonte: Pesquisa Industrial Mensal (Produção Física e de Emprego e Salário)/IBGE. Elaboração: IPEA (2008, p. 12). Obs.: Novembro/2001 = 100 com ajuste sazonal.

3 Esse trabalhador eleva consistentemente sua escolaridade no Brasil após 1995. 


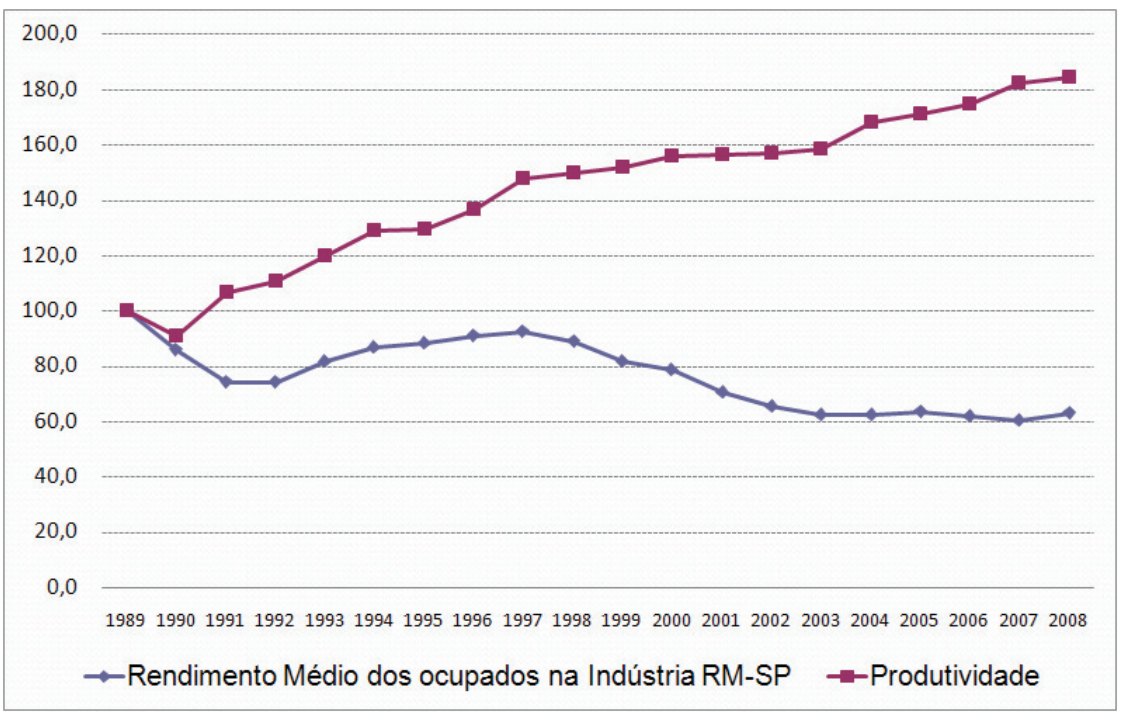

Gráfico 2 - Índice do rendimento médio real dos ocupados na indústria da Região Metropolitana de São Paulo e produtividade - 1989 a 2008. Fonte: Departamento Intersindical de Estatística e Estudos Socioeconômicos - Dieese.

Dessa forma, a magnitude da superpopulação relativa aumenta ou estabiliza-se sempre em relação com a força expansiva do capital e com os potencias da acumulação de riqueza, assim como, após 1995, no Brasil, os métodos para elevar a produtividade do trabalho coletivo são aplicados sem que os trabalhadores, enquanto classe, elevem seus rendimentos coletivos proporcionalmente. Assim, redunda-se em aumento da exploração, reduzindo-o em fragmento de ser humano, desfigurado de seu valor, imerso num estranhamento presente no processo produtivo e reduzido à categoria de peça de máquina, que por muito tempo se denominou de "[...] recursos humanos [...]" (MARX, 2009, p. 749).

Ressalta-se, ainda, que a cada período histórico pode-se evidenciar a existência do antagonismo entre a situação da classe trabalhadora e o processo de acumulação de riqueza em nossa sociedade, chegando a níveis desumanos de salários precários ou de trabalhadores tratados como mercadorias.

Contemporaneamente, é possível observar os efeitos desse processo de acumulação por meio da distribuição funcional da renda. A distri- 
buição funcional ${ }^{4}$ permite revelar o padrão de desigualdade entre as diferentes classes sociais: dos trabalhadores e dos proprietários e rentistas (FILGUEIRAS; GONÇALVES, 2007). Nos últimos 50 anos, pode-se constatar que a participação dos rendimentos do trabalho na renda nacional apresentou trajetória de queda,se comparada com a trajetória de elevação dos rendimentos advindos das propriedades (lucro, juros, aluguéis, renda da terra). No biênio 1999/2000, por exemplo, o peso do rendimento do trabalho representou apenas $40 \%$ da renda nacional, enquanto no biênio 1959/1960 era de 56,6\% (IPEA, 2010, p. 3).

Podemos exemplificar também com a seguinte decomposição: a porcentagem de salários (decorrente da venda da força de trabaIho) no Produto Interno Bruto caiu de 39,4\% em 1969 para 28,8\% do PIB em 1998, enquanto os rendimentos advindos dos lucros empresariais aumentaram de 38,2\% em 1969 para 46,3\% do PIB em 1998, e a renda dos juros e aluguéis aumentou de 22,4\% em 1969 para 24,9\% do PIB em 1998 (DEITOS, 2008, p. 33).

Registra-se, ainda, a seguinte comparação: no biênio 2008/2009, o peso do trabalho na renda nacional aumentou aproximadamente $9 \%$ em relação aos anos 1999/2000, pois passou de $40 \%$ para 43,6\%; no entanto, no biênio 2008/2009, o peso do trabalho na renda nacional diminuiu aproximadamente $30 \%$ em relação aos anos 1959/1960, pois passou de 56,6\% para 43,6\% (IPEA, 2010, p. 4).

Conclui-se que a análise das configurações da renda nacional é mais uma evidência de que a situação da classe trabalhadora permanece e se corporifica nas consequências contemporâneas do processo de acumulação de nossa sociedade.

\section{O PROCESSO DE ACUMULAÇÃO E AS RENDAS PESSOAIS E DOMICILIARES}

Entende-se que a positiva e recente combinação do crescimento econômico mais acelerado com uma elevação dos montantes

\footnotetext{
4 As sequências históricas da distribuição funcional de Deitos (2008) e do Ipea (2010a) não seguem o mesmo padrão de variáveis em virtude de alterações metodológicas na aferição nacional. Os padrões de mensuração do IBGE alteram-se no período entre 1964 a 2008. Mesmo assim, consubstanciam-se como importantes informações sobre as formas e as quantidades de apropriação da riqueza socialmente produzida.
} 
orçamentários das políticas públicas conseguiu diminuir o ritmo de aprofundamento da cisão entre a massa de renda do trabaIho e a massa de renda das propriedades (lucro, juros, aluguéis, renda da terra). Entretanto, são comuns as mudanças periódicas a cada ciclo da produção e acumulação e, mesmo com uma trajetória de redução no grau de desigualdade na distribuição funcional e pessoal da renda nos últimos quatro anos, essa redução está longe de apresentar características consistentemente relevantes para se configurar como uma mudança estrutural da distribuição funcional da renda.

É nesse sentido que, em consequência da crise internacional que explodiu em 2008, as configurações da distribuição funcional no Brasil apresentaram o seguinte movimento: uma inflexão na trajetória de recuperação da economia brasileira, ancorada na elevação do PIB e da produtividade, vem se mostrando menos favorável ao rendimento do trabalho após 2008, retornando à tendência de os rendimentos das propriedades crescerem mais rapidamente (lucro, juros, aluguéis, renda da terra), o que tem imposto a regressão na participação do trabalho na renda nacional após 2008 (IPEA, 2010).

A situação da classe trabalhadora é regulada por um desenvolvimento que é condicionado por relações de poder e pela magnitude socialmente construída da superpopulação relativa. Essa magnitude refere-se ao excedente relativo da riqueza na flutuante relação entre acumulação e rendas do trabalho.

Destaca-se a situação da classe trabalhadora após 1995, conforme Tabela 4 abaixo, em relação: à evolução da renda pessoal real média do trabalho principal de pessoas com 15 anos ou mais; à evolução da renda real domiciliar per capita; e à evolução do índice de Gini, considerado em alguns estudos como desigualdade pessoal de renda. 
Tabela 4 - Evolução do índice de Gini e da renda pessoal e domiciliar de 1992 a 2008

\begin{tabular}{|c|c|c|c|c|c|c|c|c|c|c|c|c|c|c|c|}
\hline & 1992 & 1993 & 1995 & 1996 & 1997 & 1998 & 1999 & 2001 & 2002 & 2003 & 2004 & 2005 & 2006 & 2007 & 2008 \\
\hline $\begin{array}{c}\text { Gini Brasil me- } \\
\text { tropolitano }\end{array}$ & 0,56 & 0,59 & 0,58 & 0,58 & 0,58 & 0,59 & 0,58 & 0,59 & 0,58 & 0,58 & 0,57 & 0,57 & 0,56 & 0,56 & 0,55 \\
\hline Gini Brasil & 0,58 & 0,60 & 0,60 & 0,60 & 0,60 & 0,60 & 0,59 & 0,59 & 0,59 & 0,58 & 0,57 & 0,57 & 0,56 & 0,55 & 0,54 \\
\hline $\begin{array}{c}\text { Renda pessoal } \\
\text { real média do } \\
\text { trabalho prin- } \\
\text { cipal }\end{array}$ & 710 & 740 & 902 & 940 & 930 & 924 & 851 & 855 & 828 & 771 & 778 & 808 & 872 & 902 & 920 \\
\hline $\begin{array}{c}\text { Renda domi- } \\
\text { ciliar } \\
\text { real per capita }\end{array}$ & 382 & 402 & 499 & 508 & 507 & 512 & 484 & 491 & 491 & 462 & 477 & 507 & 554 & 568 & 597 \\
\hline
\end{tabular}

Fonte: Elaboração própria a partir da Pesquisa Nacional por Amostra de Domicílios (PNAD de 1992 a 2008).Notas: A pesquisa não foi realizada em 1994 e 2000. A partir de 2004, a PNAD passou a integrar a área rural da região norte do país, à exceção do estado de Tocantins. Valores deflacionados em Reais de 2008, mediante uso do Índice Nacional de Preços ao Consumidor (INPC).

Quanto ao índice de Gini, algumas ressalvas são importantes para esta análise. O coeficiente de Gini é um índice que reflete a desigualdade relativa da distribuição interpessoal da renda, ou seja, é um indicador que mensura a desigualdade de rendimentos interpessoais, não permitindo, assim, ser tratado como sinônimo de desigualdade social ou socioeconômica (SALVADOR; AMORIM, 2010).

Salvador e Amorim (2010, p. 33) ressaltam quatro ponderações importantes relativas ao coeficiente de Gini:

A primeira é que ele mede a desigualdade entre indivíduos e não entre classes, porque por meio do coeficiente de Gini não se distingue as fontes das rendas, se é do trabalho ou se é da propriedade. O coeficiente de Gini é um instrumento pouco eficaz para medir desigualdades regionais e locais. Um exemplo disso é a dificuldade de se extrair por ele mudanças relativas às desigualdades sociais ou econômicas de uma metrópole urbana, que conjuga partes de municípios. A terceira é que se trata de um instrumento incapaz de medir a quantidade de riqueza ou de pobreza de um país, porque foi construído para medir a homogeneidade de renda em uma determinada população. Mensurar a 
partir da homogeneidade significa medir internamente as diferenças entre indivíduos de uma determinada população. É possível que dois Estados da Federação apresentem o mesmo índice de gini, mesmo que um Estado da Federação seja muito mais rico que outro, ou mesmo que a população de um Estado tenha um nível muito mais elevado de consumo que a do outro. A quarta ponderação é que apesar de ser um índice medido globalmente, as comparações entre países apresentam algumas deficiências. A principal é que o coeficiente de Gini mede relativamente a diferenças entre os indivíduos com maior renda e os indivíduos com menor renda de cada país. Esse instrumento não permite a comparação entre ricos ou pobres entre os países, porque a parcela da população com menor renda de um país pode apresentar enormes diferenças se a análise realizada comparar o acesso às necessidades humanas básicas (saúde, educação, saneamento, habitação, alimentação).

É um grande desafio para as ciências sociais superar falsos problemas deontológicos no estudo da desigualdade e o equivocado entendimento de que a pobreza é um problema e que a riqueza não o é, assim como a estratificação social não é equivalente a uma espécie de topologia natural (CATTANI, 2007). A estratificação social e as evoluções da renda, da riqueza e das configurações do trabalho estão marcadas por uma lógica intrínseca ao processo de acumulação em nossa sociedade, que configura as relações de poder, de exploração e de dominação, traduzindo-se na permanência estrutural de algumas desigualdades, e que variam conjunturalmente a depender da correlação de forças (CATTANI, 2007).

É nesse sentido que podemos realizar três apontamentos relativos à evolução do índice de Gini e da renda pessoal e domiciliar após 1995, conforme indicaram Salvador e Amorim (2010). O primeiro é que o índice de Gini do Brasil metropolitano manteve-se estabilizado de 1993 a 2003 e caiu muito lentamente de 2004 a 2008, sendo que o nível de desigualdade em 2007 era o mesmo de 1992. Isso evidencia que as mudanças nesse índice têm uma forte tendência conjuntural para o Brasil metropolitano. 
O segundo, que o índice de Gini do Brasil apresenta uma lenta, mas constante, queda da desigualdade pessoal da renda de 1993 a 2008. É inegável que, se fosse possível desconsiderar as classes sociais e por consequência a questão da posse da propriedade, poderíamos concluir que a desigualdade de renda diminuiu no Brasil. No entanto, a lenta e constante queda da desigualdade pessoal da renda de 1993 a 2008 é apenas a aparência conjuntural das desigualdades de renda no Brasil após 1995. A própria renda domiciliar real per capita evidencia a volatilidade em contagens de renda que desconsideram a questão da propriedade após 1995. A renda domiciliar, que em diversos estudos aparece como renda familiar, teve altas e quedas que se aproximam temporalmente das altas e quedas da distribuição funcional da renda, o que apresenta também a mesma tendência de redução na passagem do biênio 2008/2009, em virtude da crise datada de 2008. Destaca-se que a renda familiar média real apenas em 2006 conseguiu ultrapassar a renda familiar média real de 1996. Isso evidencia novamente que as mudanças têm uma forte tendência conjuntural e epidérmica para as famílias brasileiras em geral.

Terceiro, que a contida evolução da renda pessoal real média do trabalho principal corrobora com a análise da situação real da classe trabalhadora no Brasil após 1995. Na Tabela 4, podemos observar que, mesmo com uma alta constante da renda pessoal real média do trabalho de 2004 a 2008, o patamar em 2008 ainda está abaixo do patamar de 1996. Isso igualmente demonstra importantes tendências da conjunta em que a classe trabalhadora está inserida.

A profunda cisão entre as classes sociais não pode ser medida por indicadores per capita, assim como por outros indicadores que homogeneízam e desconsideram a brutal diferença da inserção social daqueles que dispõem de rendas das propriedades em relação com aqueles que somente dispõem das possibilidades da venda de sua força de trabalho. Isso ocorre, porque os $40 \%$ mais pobres da população vivem com $10 \%$ da renda nacional, enquanto os $10 \%$ mais ricos vivem com mais de $40 \%$ da renda nacional, assim como a renda apropriada pelo $1 \%$ mais rico é igual ao total da renda nacional apropriada pelos $45 \%$ mais pobres (IPEA, 2009). 


\section{O PROCESSO DE ACUMULAÇÃO GERA EMPOBRECIMENTO ABSOLUTO?}

Algumas precisões conceituais relativas à pauperização e à lei geral de acumulação capitalista precisam ser apontadas. Rosdolsky (2001, p. 251) apresenta as seguintes perguntas: Marx formulou a lei do empobrecimento? Na exposição da economia política de Marx encontram-se raciocínios que apontem para a ideia de que, no capitalismo, a situação da classe trabalhadora deve sofrer uma deterioração inevitável, não só em termos relativos, mas também absolutos?

Concordando com os entendimentos de Rosdolsky (2001, p. 252), entendemos que Marx não desenvolveu uma teoria do exército industrial de reserva, nem formulou uma lei de empobrecimento absoluto, mas formulou uma teoria do salário, em uma construção estruturada que oferece instrumentos analíticos muito precisos para a reflexão sobre o processo de acumulação e a situação da classe trabalhadora hoje. No próprio capítulo 23 de O Capital, intitulado de Lei Geral de Acumulação Capitalista, duas importantes sínteses parecem passar despercebidas por aqueles que acreditam que Marx formulou uma lei do empobrecimento absoluto, são elas: "[...] na medida em que o capital se acumula, a situação do trabalhador piora, seja qual for sua remuneração [...]", e "[...] essa lei produz uma acumulação de miséria proporcional (relativa) à acumulação de capital". Portanto, a teoria do salário presente n'O Capital e nos apontamentos da lei geral de acumulação capitalista é antes de tudo uma teoria do salário relativo, indicando que os contrastes e contradições sociais, assim como a situação da classe trabalhadora, pioram relativamente à riqueza socialmente construída, e não absolutamente (MARX, 1988).

Rosdolsky (2001, p. 254) destaca também que, seguramente, Engels escreveu em pleno acordo com Marx e 14 anos após a publicação do primeiro tomo de O Capital, que contém a lei geral de acumulação capitalista, as seguintes afirmações que corroboram a tese da teoria do salário relativo:

O grande mérito dos sindicatos em sua luta pela defesa do nível dos salários e a redução da jornada de trabalho consiste em lutarem por conservar e elevar 
o nível de vida da população [...]. A organização dos trabalhadores e sua resistência sempre crescente podem operar como um dique de contenção contra o aumento da miséria.

\section{O PROCESSO DE ACUMULAÇÃO E OS DIREITOS SOCIAIS}

Em meio ao processo de acumulação de nossa sociedade, os direitos sociais são determinados tanto pelas dimensões da superpopulação relativa e da pobreza absoluta, quanto pela massa de salários recebida pela classe trabalhadora. Isso porque o Estado possui autonomia relativa determinada pelas relações de força na sociedade.

A oferta da proteção social por meio de serviços que materializam os direitos sociais, entendidas como o Estado em ação, como a distribuição direta de renda pelo Estado, pode também alterar ou conservar o nível de vida da população. Dessa forma, tanto as configurações dos direitos sociais como as de distribuição de renda, podem ser alteradas no sentido da melhora das condições de vida da classe trabalhadora, por meio da luta política e/ou econômica, do desenvolvimento da consciência de classe para si própria e da alteração da correlação de forças na sociedade em prol das formas coletivas de distribuição da riqueza socialmente produzida. Essas alterações possíveis no interior de nossa sociedade podem ser realizadas, mas sob condições e relações econômicas, sociais, políticas e jurídicas.

No último quartel do século $X X$, eclodiram profundas transformações em um regime de acumulação que privilegia a acumulação e a movimentação de capitais financeiros, promovendo como seu reverso a persistência da alta desigualdade e da desproteção social.

O reverso do processo de acumulação, para Antunes (2006) é a intensificação da desconstrução e exploração do trabalho associada ao desmonte dos direitos sociais. Esse processo potencializa a insegurança social, e nem mesmo a instituição de direitos de cidadania declarados constitucionalmente foram capazes de assegurar níveis elevados de proteção social. 
Apesar da elevação constante dos níveis de acumulação e do desenvolvimento tecnológico, no contexto mundial, a acumulação flexível expõe a desumanidade legitimada socialmente, a respeito da qual destacamos os apontamentos de Marinucci e Milesi (2005) baseados em relatórios de Organismos Internacionais: em 2004, a Organização das Nações Unidas para Agricultura e Alimentação (FAO) denunciou que morria de fome uma pessoa a cada quatro segundos e que, dos 842 milhões de seres humanos que passavam fome no mundo inteiro, 798 milhões (sobre) viviam nos países em desenvolvimento; o décimo relatório anual do Fundo das Nações Unidas para a Infância (Unicef), Situação Mundial da Infância 2004, revela que, de o a 15 anos aproximadamente, uma em cada duas crianças vivia com alimentação não adequada, sem acesso à educação nem à água potável, sendo ainda que $45 \%$ dessas crianças eram vítimas de conflitos bélicos, 1,2 milhões eram traficadas e 2 milhões eram exploradas sexualmente (MARINUCCI; MILESI 2005) 5 .

As conquistas civilizatórias estão permanentemente em disputa, e no âmbito de cada país se revelam as especificidades desses limites. Independentemente dos limites práticos e teóricos da estrutura de nossa sociedade, o Estado permanece sendo o grande regulador e a fonte de mediação entre a classe trabalhadora e a riqueza socialmente produzida.

O Estado não é um ente parassocial, é parte integrante da sociedade, é parte decisiva da correlação de forças da própria sociedade e têm na gerência do fundo público um dos elementos fundamentais de sua intervenção. Apesar do caráter mundializado da pobreza e da alta desigualdade, o nível de suas consequências aviltantes depende das ações estatais de cada país e dos limites de sua soberania. O Estado desempenha um papel indispensável, na garantia da proteção social em geral, perpassado diretamente por suas ações e não ações.

Nas últimas décadas, houve uma reação conservadora marcada pela promoção do esvaziamento da possibilidade de uma ampliação substantiva da cidadania, que limitou os sistemas públicos de

5 As informações da FAO podem ser encontradas em EL ESTADO... (2003). E as informações do Unicef podem ser encontradas em SITUAÇÃO... (2004). 
proteção social, em grande medida por meio da apropriação do fundo público (PEREIRA, 2006).

O fundo público exerce uma função central na materialização dos direitos sociais. O fundo público no capitalismo contemporâneo ocupa indiscutível lugar estrutural, como expressão da maturidade da formação Estatal, que se apropria de parcela significativa da mais-valia socialmente produzida para assegurar as condições gerais de produção e reprodução,apresentando destacadamente o desenvolvimento de políticas sociais como lugar relevante de alocação desses recursos (BEHRING, 2004, p. 164).

Nos países em que se construíram sistemas de proteção social que privilegiavam a redistribuição da renda gerada por meio dos fundos públicos, com tributação sobre os mais ricos e sobre as rendas das propriedades e transferências dos recursos dos fundos para os mais pobres, o Estado Social não tratou apenas de disponibilizar serviços sociais e garantir renda aos pobres, mas tratou principalmente de retirar das forças de mercado o monopólio da expansão econômica e da gestão sobre a força de trabalho (POCHMANN, 2004).

No Brasil, sempre houve um alto nível de tensão entre o ideal de sobrevivência individualista (defesa da acumulação privada) e o ideal de enfrentamento da alta desigualdade e do elevado nível de insegurança social. Essa tensão entre o ideal de mercado e o trabalho assalariado no Brasil guiou diversas concepções conformadas dos direitos sociais, sob o argumento da escassez de recursos, em programas inspirados em ideais de mínimos sociais. Essa visão, em geral, desconsidera que a taxa de juros do Brasil está entre as maiores do mundo e que a consequência direta de um sistema baseado em juros altos é a considerável transferência de recursos do fundo público para o sistema financeiro.

Nesse contexto, são relevantes instrumentos de ação Estatal, defendidos hegemonicamente nas últimas décadas: o superávit primário e a desvinculação de receitas estatais. Pode-se questionar: qual a relação entre os direitos sociais e esses instrumentos?

Os direitos sociais são materializados pelas políticas sociais; estas substantivam a concretude da cidadania e pressupõem a destina- 
ção de excedente acumulado nas bases do fundo público para a proteção social, que é por princípio desmercantilizada.

No Brasil, os desafios impostos à ampliação da cidadania e da garantia dos direitos sociais se destacam em escala ampliada e diversificada.

Soares (2003) sinaliza a condição da classe trabalhadora como um verdadeiro desajuste social, situado no agravamento das condições preexistentes de desigualdade estrutural, intensificado com o impacto das políticas desregulamentadoras do trabalho e da vida social.Resulta disso, também, um aumento da desproteção social originada em sistemas de proteção social que tendem a vincular a relação salarial com as possibilidades de acessos aos serviços de proteção social (SOARES, 2003). Compreende-se, assim, que o desemprego e a precarização do trabalho não são entendidos como problemas advindos da estagnação econômica ou da economia em crise, são entendidos como problemas advindos estruturalmente das consequências dos processos fundamentais de acumulação que se materializam na vida cotidiana da classe trabalhadora (CATTANI, 2000).

Nesse sentido, destaca-se a tensão gerada pela associação entre proteção social e inserção laboral. Isso porque com o aprofundamento do esvaziamento do fundo público, características como aumento do desemprego, redução da capacidade de consumo dos salários, intensificação e parcialização do trabalho promovem associadamente perdas na proteção social coletiva. Essas perdas levam as escolhas tendentes a direcionar a proteção social para o paradigma contributivo em detrimento de um paradigma universalista. A consequência central é a tendência de excluir do acesso à proteção social aqueles que não podem participar contributivamente para o sistema, em conjunto com a tendência de desenhos emergenciais, contingenciais e precários de proteção social.

Ressaltamos, ainda, que o acesso aos direitos sociais pela classe trabalhadora é, em grande medida, resultante das configurações já explicitadas em relação à renda do trabalho, como também dos efeitos estabelecidos na gestão do fundo público pelo Estado. 
Conforme apresentado por BIN (2010b), o Gráfico 3 traz uma amostra de quanto os juros reais - aquilo que excede à inflação são apropriados pelo Estado, por meio do Tesouro Nacional, para remunerar os compradores de títulos vinculados à taxa Selic, na qual, ao lado dos juros, figura o investimento do Tesouro, além das Desvinculações constitucionais de Receitas da União (DRU). Desde 1998, os investimentos do Tesouro Nacional têm sido sistematicamente superados pelos juros reais apropriados, assim como, nesse período, os juros reais equivaleram a uma média anual de cerca de treze por cento das receitas tributárias federais quando analisamos apenas a parcela da dívida vinculada à taxa Selic (BIN, 2010b, p. 11). A DRU é um mecanismo de apropriação do fundo público da seguridade social e da educação para valorização do capital financeiro, caminhando na direção oposta à das conquistas sociais da Constituição Federal de 1988 (SALVADOR, 2010, p. 370). A DRU, criada para dar ao poder executivo maior liberdade de gasto, vem se mantendo como mais uma expressão reveladora do caráter de classe do Estado, na sua versão financeira, pois foi criada com o objetivo não explícito de alcançar superávits primários e pagamento de juros da dívida (BIN, 2010, p. 91).

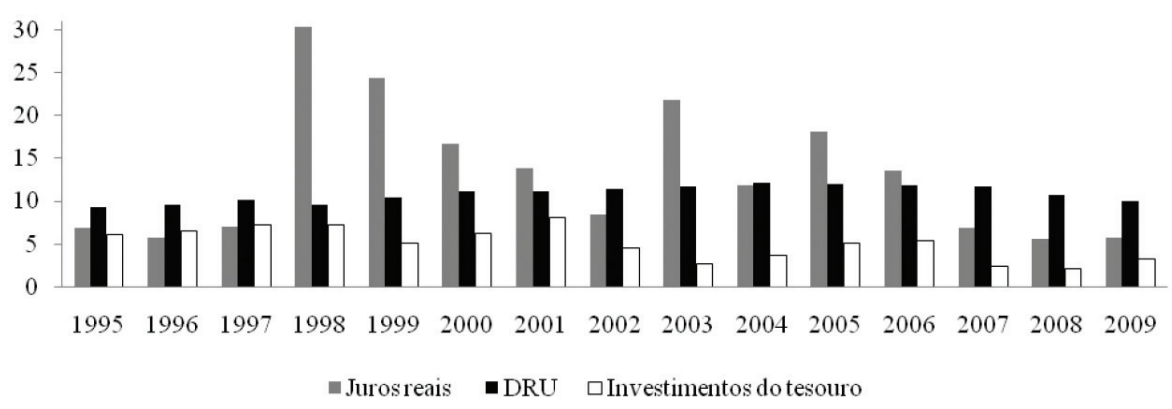

Gráfico 3 - Juros à Taxa Selic, DRU e Investimentos do Tesouro no Brasil. Fonte: Banco Central (BC), Instituto de Pesquisa Econômica Aplicada (IPEA) e Secretaria do Tesouro Nacional (STN).Elaboração: Bin (2010b, p. 11). Obs.: i) escala percentual; ii) estimativas em relação à arrecadação de impostos e contribuições federais, exceto previdenciárias. A partir de 2000, o mecanismo de desvinculação se estabilizou como DRU. No período anterior a 2000, os mecanismos de desvinculação apresentaram variações de nomenclaturas, sem perder a essência de seu sentido e impacto. 
Conforme se observa no Gráfico 4, nos últimos 15 anos houve uma escalada dos valores gastos com juros e amortizações da dívida pública. Ainda que o Gráfico 5 não inclua o refinanciamento da dívida pública, observa-se que essa escalada concorre diretamente e relevantemente com os recursos destinados a materializar os direitos sociais. Dessemodo, pode-se observar de forma concreta a voracidade da escalada dos recursos públicos concedidos à finança, ou seja, aos portadores de propriedades financeiras.

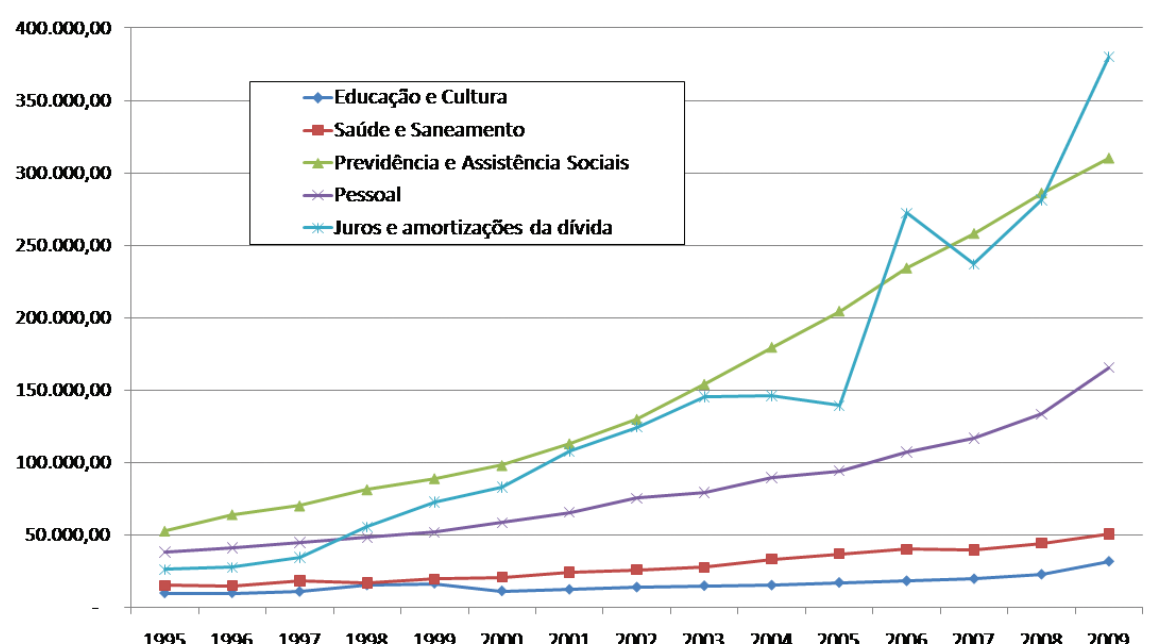

Gráfico 4 - Gastos selecionados do Orçamento Geral da União - R\$ milhões correntes.

Fonte: Secretaria do Tesouro Nacional. Elaboração: AUDITORIA...[200-?]. Obs.: não inclui o refinanciamento da dívida pública.

No período de 1995 a 2009, a desvinculação de receitas significou um importante acréscimo de recursos de livre aplicação, equivalentes a uma média de onze por cento das receitas com tributos federais (BIN, 2010, p. 92). Na luta pela mais-valia apropriada pelo Estado, a DRU concede à finança uma importante vantagem de classe (BIN, 2010, p. 94). Nesse sentido, Salvador (2010, p. 370) aponta que a DRU é peça-chave na estratégia da política fiscal para a composição do superávit primário e que

[...] as políticas sociais mais prejudicadas pelo mecanismo da DRU são as da seguridade social e da educação. Na educação, estima-se que os mecanismos de desvinculação de recursos (FSE, FEF e DRU) 
retiraram, em 12 anos (1994 a 2006) e em valores corrigidos pela inflação, R\$ 72 bilhões (Iwasso e Cafardo, 2007). Apenas no período de vigência da DRU (2000 a 2007), R\$45,8 bilhões deixaram de ser aplicados no setor. Em 2007, o Ministério da Educação (MEC) deixou de contar com R\$ 7,1 bilhões. $O$ mecanismo é muito simples: a Constituição determina que $18 \%$ dos recursos arrecadados em impostos federais sejam aplicados em Educação, mas esse valor é calculado após a retirada dos recursos da DRU. Por consequência, em vez dos $18 \%$ previstos na Carta Magna são aplicados somente $13 \%$ na educação.

Esse mecanismo - de desvinculação de receitas - iniciou-se em 1995 e está prorrogado até 2011 . Com ele, mais de $20 \%$ das receitas da Seguridade Social foram desvinculados, sendo que, no período de 1995 a 2005, as desvinculações de receita totalizaram $\mathrm{R} \$ 267$ biIhões, dos quais $\mathrm{R} \$ 107$ bilhões estão além do limite legalmente autorizado para a DRU (GENTIL, 2006; 2007). Entre as despesas que a DRU financia, estão os juros e a amortização da dívida pública, para que se possa minimizar o déficit orçamentário fiscal - numa tendência de esvaziamento dos fundos públicos da Seguridade Social e, por conseguinte, dos direitos sociais.

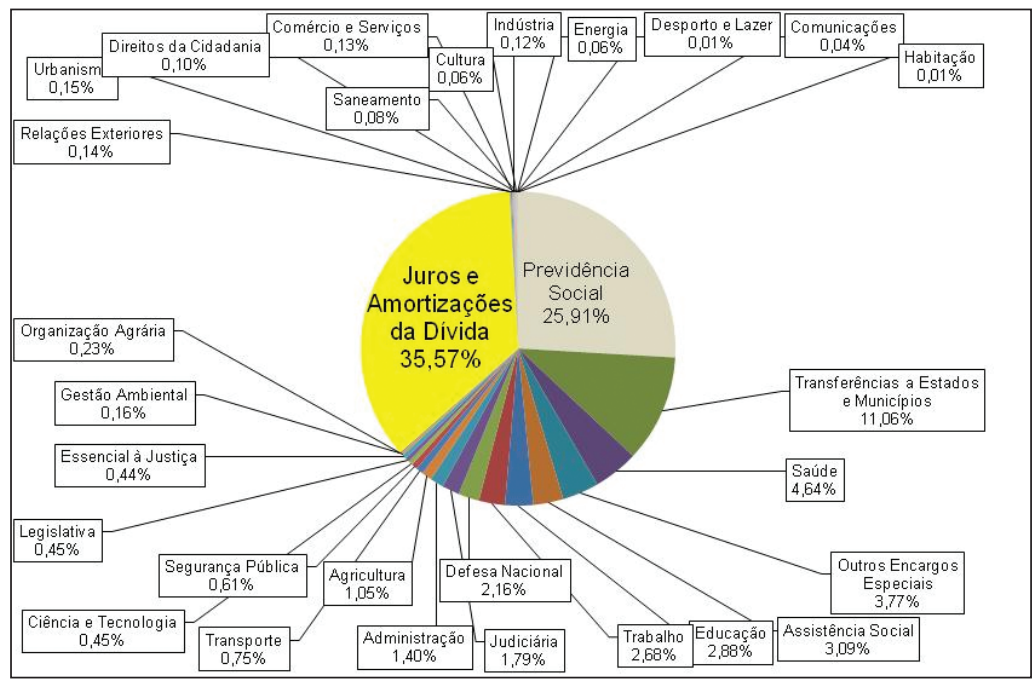

Gráfico 5 - Gastos selecionados do Orçamento Geral da União - R\$ milhões correntes.

Fonte: Secretaria do Tesouro Nacional. Elaboração: AUDITORIA...[200-?]. Obs.: não inclui o refinanciamento da dívida pública. 
No Brasil, conforme os Gráficos 4 e 5, por meio do Orçamento Geral da União podem ser observados fatores de perpetuação da insegurança de renda, do esvaziamento das políticas sociais e da não garantia dos direitos sociais. De acordo com a Secretaria do Tesouro Nacional (STN $)^{6}$, em 2009, de todos os montantes pagos pela União, 40,8\% foram destinados ao refinanciamento e aos serviços (juros, amortizações da dívida, e outros) das dívidas interna e externa. De acordo, ainda, com esse órgão, nesse mesmo ano, de todos os montantes pagos pela União, 29,7\% foram destinados para a soma das seguintes funções governamentais: Ciência e Tecnologia; Saneamento; Educação; Saúde; Previdência Social e Assistência Social. A partir desse quadro, que se repete em outros países da América Latina, fica claro que, estruturalmente, indivíduos que recebem rendas das propriedades (incluindo as financeiras) acumulam enormes montantes em detrimento das necessidades da coletividade (PEREIRA; AMORIM, 2010). Essa concepção se fortalece ao se observar que na América Latina $0,1 \%$ das famílias detêm um estoque de riqueza proveniente da posse da propriedade de bens produtivos e especulativos (terras, empresas, ativos financeiros), o que corresponde a um patrimônio de mais de 620 bilhões de dólares (POCHMANN, 2006).

Mesmo em meio aos atuais desenvolvimentos tecnológicos e à elevação continuada da produtividade, perpetuam-se, de maneira mais generalizada no Brasil e na América Latina, a desproteção e a insegurança social (PEREIRA; AMORIM, 2010). Permanece também um número assustador de pobres na América Latina que beiram o quantitativo total da população brasileira. Nesse sentido, corrobora-se com o questionamento de Marcio Pochmann (2009) sobre se essa situação precisaria realmente existir. Pochmann (2009) se refere ao fenômeno da destituição de direitos sociais como mediocridade histórica, uma vez que 1,5 milhões de clãs centralizam quase dois terços da riqueza de todo o mundo. Ademais, esse autor acrescenta que, no Brasil, os ricos e proprietários são os grandes beneficiados pela financeirização da riqueza.

Os ricos proprietários e rentistas usufruem a quase servidão de uma massa populacional que vive a exercer atividades serviçais

6 O Orçamento Geral da União contabilizado pela Secretaria do Tesouro Nacional está disponível em: PORTAL... [200-?]. 
e que, possuindo somente a própria força de trabalho, são excluídas desde a infância de suas necessidades humanas básicas (POCHMANN, 2009). A desproteção social e a precária materialização dos direitos sociais não são condições necessárias; e as evidências apresentadas neste artigo somam-se para afirmar e sintetizar que essas iniquidades não são um fenômeno natural, assim como sua existência não é resultado de um alto crescimento da população associado a um crescimento insuficiente da riqueza social (PEREIRA; AMORIM, 2010). Em síntese, a dinâmica do orçamento público - os recursos públicos - não está voltada para o atendimento da enorme dívida social, mas, fundamentalmente, para a sustentação da dívida financeira do setor público, na qual o ajuste fiscal promove como nexo causal um enorme desajuste social (POCHMANN, 2009).

Dessa forma, os efeitos da superpopulação relativa somados aos efeitos da dinâmica do orçamento público qualificam e determinam de forma ampla como as necessidades da acumulação limitam as possibilidades dos direitos sociais.

\section{REFERÊNCIAS}

ANTUNES, Ricardo. As formas contemporâneas de trabalho e a desconstrução dos direitos sociais. In: SILVA, Maria Ozanira da Silva;YAZBEK, Maria Carmelita (Org.). Políticas públicas de trabalho e renda no Brasil contemporâneo. São Paulo: Cortez; São Luís: FAPEMA, 2006. AUDITORIA Cidadã da Dívida. [200-?]. Disponível em: <http://www. divida-auditoriacidada.org.br/>. Acesso em: 6 nov. 2010.

BEHRING, Elaine. Política social: notas sobre o presente e o futuro. In: BOSCHETTI, Ivanete et al. (Org.). Política social: alternativas ao neoliberalismo. Brasília: UnB, Programa de Pós-Graduação em Política Social, Departamento de Serviço Social, 2004.

BIN, Daniel. Dívida pública, classes e democracia no Brasil pós-real. 2010. 286 f. Tese (Doutorado em Sociologia)-Programa de Pós-Graduação em Sociologia, Departamento de Sociologia, Universidade de Brasília, Brasília, 2010.

. Dívida pública e (anti)democracia econômica no Brasil do real. 
In: SEMINÁRIO NACIONAL SOCIOLOGIA \& POLÍTICA, 2., 2010, Curitiba. Anais eletrônicos... Curitiba: Universidade Federal do Paraná, 2010b. Disponível em:<http://www.seminariosociologiapolitica. ufpr.br>. Acesso em: 10 jan. 2011.

BRASIL. Senado Federal. Portal orçamento. [200-?]. Disponível em:<http://www9.senado.gov.br/portal/page/portal/orcamento senado >. Acesso em: 24 fev. 2010.

CADASTRO Geral de Empregados e Desempregados - CAGED: base de dados. Disponível em: <http://www.caged.gov.br> . Acesso em: 30 maio 2011.

CARVALHO, Ruy de Quadros; BERNARDES, Roberto. Reestruturação industrial, produtividade e desemprego. São Paulo em Perspectiva, São Paulo, v. 10, n. 1, p. 53-62, 1996.

CATTANI, Antonio David. Riqueza: totem e tabu. Sociologias, Porto Alegre, v.9, n. 18, p. 14-21, jul./dez. 2007.

.Trabalho e autonomia. 2. ed. Petrópolis: Vozes, 2000.

CHESNAIS, François. A mundialização do capital. São Paulo: Xamã, 1996.

DAL ROSSO, Sadi. Mais Trabalho!: a intensificação do labor na sociedade contemporânea. São Paulo: Boitempo, 2008.

DEITOS, Roberto Antonio. Economia e Estado no Brasil. Revista HISTEDBR Online, Campinas, n. 29, p. 20-34, mar. 2008. Disponível em: <http://www.histedbr.fae.unicamp.br/revista/edicoes/29/ Art02_29.pdf>.

DEPARTAMENTO INTERSINDICAL DE ESTATÍSTICA E ESTUDOS SOCIOECONÔMICOS (Brasil). Mercado de trabalho Brasileiro: evolução recente e desafios. Brasília, DF, 2010. Disponível em: <http:// www.dieese.org.br>. Acesso em: 13 nov. 2010

EL ESTADO de la inseguridad alimentaria em el mundo 2003. Roma: FAO, 2003. Disponível em: <http://www.fao.org/docrep/006/ j0083s/j0083s00.htm>. Acesso em: nov 2010.

FILGUEIRAS, Luiz; GONÇALVES, Reinaldo. A economia política do governo Lula. Rio de Janeiro: Contraponto, 2007.

GENTIL, Denise Lobato. A Política Fiscal e a Falsa Crise da Se- 
guridade Social Brasileira: análise financeira do período 19902005. 2006. 245 f. Tese (Doutorado em Economia)-Instituto de Economia da Universidade Federal do Rio de Janeiro, Rio de Janeiro, 2006.

- A Política Fiscal e a falsa crise do sistema de seguridade social no Brasil: análise financeira do período recente. In: SICSÚ, João (Org.). Arrecadação (de onde vem?) e gastos públicos (para onde vão?). São Paulo: Boitempo, 2007.

IANNI, Octavio. Estado e Capitalismo. 2. ed. São Paulo: Brasiliense, 2004. IPEADATA: Base de dados econômicos e financeiros. Disponível em: <http://www.ipeadata.gov.br>. Acesso em: 30 maio 2011.

IPEA. Pobreza e riqueza no Brasil metropolitano. Comunicado da presidência, Brasília, n. 7, ago. 2008. Disponível em: <http:// desafios2.ipea.gov.br/portal/images/stories/PDFs/comunicado/080804_comunicadoipea07.pdf>.

IPEA. Desenvolvimento. Desafios. Edição 52, Jul. 2009. Disponível em: <http://desafios2.ipea.gov.br/portal/index.php?option=com_ content\&view=article\&id=3211>Acesso em: 15 ago. 2010.

IPEA. Pnad 2008: primeiras Análises. Comunicado da Presidência, Brasília, n. 30, 24 set. 2009.

IPEA. Distribuição funcional da renda pré e pós crise internacional no Brasil. Comunicados do IPEA, Brasília, n. 47,2010.

MARINUCCI, Roberto; MILESI, Rosita. Migrações internacionais contemporâneas. Brasília: Instituto Migrações e Direitos Humanos, jun. 2005.

MARX, Karl. O Capital. 3. ed. São Paulo: Nova Cultural, 1988. V. 1.

. O Capital: crítica da Economia Política. 22. ed. Rio de Janeiro: Civilização Brasileira, 2008.

. O Capital: crítica da economia política. 23. ed. Rio de Janeiro: Civilização Brasileira, 2009.

MOROSINI, Marília C. Qualidade da educação universitária: isomorfismo, diversidade e equidade.Interface-Comunicação, Saúde, Educação, São Paulo, v. 5, n. 9, p. 89-102, ago. 2001. Disponível em: 
<http://www.scielo.br/pdf/icse/v5ng/06.pdf>.

PEREIRA, Camila Potyara; AMORIM, Álvaro André Santarém. Pobreza no Brasil e na América Latina: concepções restritas sobre realidades complexas. Revista Argumentum, Vitória, v. 2, n. 2, p. 132148, 2010. Disponível em: <http://periodicos.ufes.br/argumentum/ article/view/949/689>.

PEREIRA, Larissa Dahmer. A reação burguesa à crise capitalista e o processo de mercantilização do ensino superior no pós-1970. Revista Virtual Textos \& Contextos, n. 5, p. 1-21, nov. 2006. Disponível em: <http://revistaseletronicas.pucrs.br/ojs/index.php/fass/article/ viewFile/1023/803>.

PEREIRA, Potyara A. P. Necessidades humanas: subsídios à crítica dos mínimos sociais. São Paulo: Cortez, 2000.

POCHMANN, Marcio. Proteção social na periferia do capitalismo: considerações sobre o Brasil. São Paulo em Perspectiva, São Paulo,ano 18, n. 2, abr./jun. 2004.

.Qual desenvolvimento?: oportunidades e dificuldades do Brasil contemporâneo. São Paulo: Publisher Brasil, 2009.

.Riqueza e concentração de renda. In: LATINOAMERICA. Enciclopédia contemporânea da América Latina e do Caribe. São Paulo: LPP; Boitempo, 2006.

ROSDOLSKY, Roman. Gênese e estrutura de 0 Capital de Karl Marx. Rio de Janeiro: EDUERJ: Contraponto, 2001.

SALVADOR, Evilasio; AMORIM, Álvaro André Santarém. Abordagens das Desigualdades Socioeconômicas no Brasil do Século XXI. Revista Em Pauta, Rio de Janeiro, n. 26, 2010.

SITUAÇÃO Mundial da Infância 2004: meninas, educação e desenvolvimento. New York: UNICEF, 2004. Disponível em: <http:// www.unicef.pt/docs/pdf_publicacoes/situacao_mundia_da_infancia_2004.pdf>. Acesso em: nov. 2010.

SOARES, Laura Tavares. O desastre social. Rio de Janeiro: Record, 2003. 